\title{
Inactivation of enveloped and non-enveloped viruses on seeded human tissues by gamma irradiation
}

\author{
Mark A. Moore
}

Received: 7 February 2011/Accepted: 25 June 2011/Published online: 3 August 2011

(C) The Author(s) 2011. This article is published with open access at Springerlink.com

\begin{abstract}
Human tissue allografts are widely used in a variety of clinical applications with over 1.5 million implants annually in the US alone. Since the 1990s, most clinically available allografts have been disinfected to minimize risk of disease transmission. Additional safety assurance can be provided by terminal sterilization using low dose gamma irradiation. The impact of such irradiation processing at low temperatures on viruses was the subject of this study. In particular, both human tendon and cortical bone samples were seeded with a designed array of viruses and the ability of gamma irradiation to inactivate those viruses was tested. The irradiation exposures for the samples packed in dry ice were 11.6-12.9 kGy for tendon and 11.6-12.3 kGy for bone, respectively. The viruses, virus types, and log reductions on seeded tendon and bone tissue, respectively, were as follows: Human Immunodeficiency Virus (RNA, enveloped), $>2.90$ and $>3.20$; Porcine Parvovirus (DNA, non-enveloped), 1.90 and 1.58; Pseudorabies Virus (DNA, enveloped), 3.80 and 3.79; Bovine Viral Diarrhea Virus (RNA, enveloped), 2.57 and 4.56; and Hepatitis A Virus (RNA, non-enveloped), 2.54 and 2.49, respectively. While proper donor screening, aseptic technique, and current disinfection practices all help reduce the risk of viral transmission from human allograft tissues, data
\end{abstract}

M. A. Moore $(\square)$

LifeNet Health, 1864 Concert Drive, Virginia Beach,

VA 23453, USA

e-mail: mark_moore@lifenethealth.org presented here indicate that terminal sterilization using a low temperature, low dose gamma irradiation process inactivates both enveloped and non-enveloped viruses containing either DNA or RNA, thus providing additional assurance of safety from viral transmission.

Keywords Viral inactivation - Gamma irradiation · Bone allografts $\cdot$ Soft tissue allografts $\cdot$ Sterilization
Abbreviations
AATB American association of tissue banks
BVDV Bovine viral diarrhea virus
CDC Center for disease control
$\mathrm{D}_{10} \quad$ In this context, the radiation dose required for one $\log$ reduction of viral load
DNA Deoxyribonucleic acid
FrhK-4 Fetal rhesus monkey kidney
HAV Hepatitis A virus
$\mathrm{HCV}$ Hepatitis $\mathrm{C}$ virus
HIV Human immunodeficiency virus
NAT Nucleic acid testing
PPV Porcine parvovirus
PrV Pseudorabies virus
RNA Ribonucleic acid
SAL Sterility assurance level

\section{Introduction}

Human tissue allografts are widely used in a variety of clinical applications. In particular, the use of bone 
and soft tissue allografts for orthopedic repair has gained wide acceptance over the past two decades (Zhang et al. 1994; Peterson et al. 2001; Fanelli et al. 1996; Gasser and Uppal 2006; Mirzayan 2005). The American Association of Orthopedic Surgeons estimates that over 1.5 million musculoskeletal allografts are used annually (Joyce et al. 2008). Since the 1990s, most clinically available allografts have been disinfected to minimize risk of disease transmission. However, disease transmission is still a risk as highlighted by a 2002 Center for Disease Control (CDC) investigation which identified twenty-six cases of bacterial infections that stemmed from allograft tissue, one of which resulted in the death of a 23-year-old man (Jones et al. 2007; Grieb et al. 2006; Vangsness et al. 2006; CDC report 2002; Kainer et al. 2004). The perceived risk of postoperative infection is noted by several authors as the single largest potential disadvantage in choosing an allograft (McGuire and Hendricks 2009; Shino et al. 2002). While risk of infection or disease transmission is thought to be a major disadvantage of allografts, an American Academy of Orthopedic Surgeons tissue work group (Joyce et al. 2008), reports "Disease transmission is rare when comparing reports of infection versus number of allografts distributed/ yr." The tissue banking community has responded to the remaining risk by developing methods to terminally sterilize allograft tissues in their final package (Joyce et al. 2008). The provision of sterile allograft tissue, which is practiced by some tissue banks, can be accomplished by following several steps which include donor screening, microbiological testing, aseptic recovery and processing, disinfection, and, finally, terminal sterilization (McAllister et al. 2007). These processes can be validated to yield a microbial sterility assurance level (SAL) of $10^{-6}$ at a low dose of irradiation (Baker et al. 2005; Moore et al. 2004; Nguyen et al. 2011). An SAL of $10^{-6}$ indicates there is a 1 out of 1,000,000 chance that a viable organism exists with any single graft (Vangsness et al. 2003). Achieving this SAL by a validated process allows labeling of terminally sterilized allografts as sterile (ANSI/AAMI 2008). To address clinical effectiveness, this terminal irradiation sterilization process has also been demonstrated to have no significant impact on biomechanical or biological properties (Balsly et al. 2008; McGilvray et al. 2005; Greaves et al. 2008; Goertzen et al. 1995; Rihn et al. 2006).
In addition to microbial sterility, however, the elimination of viruses is essential in assuring tissue safety. In March of 2005, the American Association of Tissue Banks (AATB) sought to further reduce the risks of Human Immunodeficiency Virus (HIV) and Hepatitis C Virus (HCV) transmission by requiring nucleic acid testing (NAT) in donor screening procedures (Rigney 2004). NAT has been shown to markedly reduce the window period of these viruses and was incorporated into blood banking procedures, effectively reducing the risk of $\mathrm{HIV}$ and $\mathrm{HCV}$ transmission from 1 in 1.5 million blood units and 1 in 276,000 blood units, respectively, to 1 in 2 million blood units for either virus (Stramer et al. 2004). Also, the introduction of NAT has halved the window period for HIV-1 to 12 days from the previous 22 day antibody window (McGuire and Hendricks 2009). Encouragingly, one report indicates that no instances of viral transmission are reported to have ever occurred from tissue processed following proper donor screening procedures that include HIV testing (Peterson et al. 2001). While NAT screening reduces viral risks, these methods only address specific viruses. Previously Chen (2008) described the impact of disinfection processing solutions (US Patents 5,556,379; 5,820,581; 5,977,034; 6,024,735) on a variety of enveloped and non-enveloped viruses. While these processes, in addition to proper screening and NAT, greatly reduce any risk of viral transmission, terminal sterilization has the potential to provide greater assurance of viral safety. Specifically, gamma irradiation has been demonstrated to lead to viral inactivation even at low dosages. (Campbell et al. 1994; Conway et al. 1991; Dugan and Trujillo 1975; Fideler et al. 1995; Grecz et al. 1987; Grieb et al. 2005, 2006; House et al. 1990; Kaupert et al. 1999; Miekka et al. 1998; Pelka et al. 1993; Pruss et al. 2002; Sullivan et al. 1973; Thomas et al. 1982). However indicative, these studies were not comprehensive to the wide array of target viruses, tissues, and desired irradiation conditions.

While these numerous studies all addressed various viruses and conditions, we sought to perform a comprehensive assessment of the impact of gamma irradiation at low temperatures on both seeded human tendon and cortical bone and to examine a designed array of viruses in a single study. Low temperature irradiation exposure was chosen as this has previously been shown to minimize free radical generation 
and tissue damage (Anderson et al. 1992; Hamer et al. 1999). Viruses were chosen to represent an array of enveloped, non-enveloped, RNA, and DNA viruses, and included Human Immunodeficiency Virus (HIV), Porcine Parvovirus (PPV), Pseudorabies Virus (PrV), Bovine Viral Diarrhea Virus (BVDV), and Hepatitis A Virus (HAV). Here, the hypothesis that low temperature gamma irradiation of seeded human tendon and bone would result in the reduction of a comprehensive array of RNA, DNA, enveloped, and non-enveloped viruses was tested.

\section{Methods}

The study design was to separately seed tendon and bone human tissues with a designed array of viruses and then subject the separate tissues to low temperature, low dose gamma irradiation, and test for surviving viruses. Human tibialis tendons and cortical bone derived from long bones were obtained with generous research authorization. Tendon and cortical bone used in the study came from multiple donor sources. Bone tissue was from two male donors, ages 55 and 77. Tendon was from two male and two female donors, ages 20, 55, 64, and 64, respectively. However, to provide internal control, each individual virus tested per tissue type was tested with a single donor tissue. As an example, all tests for recovery, interference, toxicity, viral reduction, and time $=0$ controls to test, e.g., HIV with tendon were perform using individual tendon samples from a single donor. Prior to use, all donors were serologically screened by either antibody or nucleic acid testing and the absence of the following agents was confirmed: Hepatitis B,
Hepatitis C, HIV, and HTLV. The individual tissue portions tested consisted of a single, intact cortical bone piece or tendon segment, respectively. Prior to seeding and irradiation, tissues were processed using the Allowash ${ }^{\circledR}$ disinfection technology (US Patents $5,556,379 ; 5,820,581 ; 5,977,034 ; 6,024,735)$ to mimic the anticipated tissue condition prior to terminal irradiation. In order to perform a comprehensive study, an array of viruses was tested to include every permutation of DNA, RNA, enveloped, and nonenveloped characteristics. In addition, a specific environmentally relevant virus (HIV) was included. The viruses tested thus included: HIV, HTLV-IIIB strain, an $80-130 \mathrm{~nm}$ enveloped RNA containing retrovirus; PPV, NADL-2 strain, an 18-26 nm, nonenveloped, DNA-containing parvovirus; PrV, SHOPE strain, a 150-200 nm, enveloped, DNA-containing virus; BVDV, Singer strain, a 50-70 nm, enveloped RNA-containing pestivirus; and HAV, HM175 strain, 18f, a $28-30 \mathrm{~nm}$, non-enveloped, RNA-containing picornavirus. To qualify the test methodology, toxicity and interference studies were performed at the testing facility (Wuxi Apptec, Philadelphia, PA). To prepare samples for indicator cell toxicity, $1 \mathrm{~g}$ tissue portions were mock-spiked with $0.5 \mathrm{~mL}$ of virus suspension media and allowed to absorb into the tissue for $15 \mathrm{~min}$ at $2-8^{\circ} \mathrm{C}$, followed by tissue homogenization (tendon) or suspension (bone) in a total of $9.5 \mathrm{~mL}$ of virus resuspension media. Serial dilutions (in serum-free media) of this solution were tested for toxicity against the virus indicator cell lines appropriate for each virus (see Table 1). Serial dilutions (in serum-free media) of this solution were tested for toxicity against the virus indicator cell lines appropriate for each virus (see Table 1). Cell

Table 1 Viral reduction-human tendon (all values in $\log$ )

\begin{tabular}{|c|c|c|c|c|c|}
\hline Virus & HIV & PPV & PrV & BVDV & HAV \\
\hline Indicator cell line & CEM-A & ST & $\mathrm{CV}-1$ & BT & FrhK-4 \\
\hline Titer-seeded & 6.84 & 6.72 & 7.06 & 7.82 & 8.40 \\
\hline Gamma- $_{\mathrm{o}}$ & 5.47 & 5.96 & 5.77 & 7.23 & 7.89 \\
\hline Gamma-treated & $<2.57$ & 4.06 & 1.97 & 4.66 & 5.35 \\
\hline Total log reduction & $>2.90$ & 1.90 & 3.80 & 2.57 & 2.54 \\
\hline Approximate $\mathrm{D}_{10}$ value & $<4$ & 6 & 3 & 5 & 5 \\
\hline
\end{tabular}

Viral reduction of seeded human tendon treated with gamma irradiation at low temperatures. Shown are the indicator cell lines, titer seeded onto allograft, titer of recovered virus from seeded grafts $\left(\mathrm{Gamma}-\mathrm{T}_{0}\right)$, titer of recovered virus from seeded and irradiated grafts $\left(\right.$ Gamma- $\left.\mathrm{T}_{0}\right)$, and total $\log$ reduction (Gamma- $\mathrm{T}_{0}$ minus Gamma-treated). Also shown is a rounded approximate $\mathrm{D}_{10}$ value calculated by dividing the 11.6-12.9 kGy dose by the total log reduction and assuming a linear dose-response relationship 
monolayers were read by visually evaluating the percentage of monolayer remaining per surface area of the well. No toxicity was observed in the negative control wells; therefore $100 \%$ of the monolayer was present and intact. For the test sample, if toxicity was observed (i.e., a percentage of that monolayer was missing), that percentage was determined visually by comparison to the negative control. One technician determined the percentage of cytotoxicity (if any) and a second operator was required for verification. Samples which reduced the cell numbers below $80 \%$ of controls were considered toxic. Extracts prepared to test interference were likewise prepared, followed by dilution to a non-toxic level, as determined by the toxicity assay. Then, samples were spiked to $5 \% \mathrm{v} / \mathrm{v}$ with virus stock solution. Controls consisted of serumfree media also spiked to $5 \% \mathrm{v} / \mathrm{v}$ with virus stock solution. Samples which altered the virus titer by $>0.5$ $\log _{10}$ were considered to interfere. The experimental groups (Gamma-treated), were prepared by seeding $0.5 \mathrm{~mL}$ of a high titer viral solution (see Tables 1,2) on $1 \mathrm{~g}$ of tissue and allowing absorption for $15 \mathrm{~min}$ at $2-8^{\circ} \mathrm{C}$. These tissues were placed into a container on dry ice and shipped for irradiation using a ${ }^{60} \mathrm{Co}$ source (Steris, Morton Grove, IL). The irradiation was performed while the samples were still stored on dry ice to maintain low temperatures. The container had previously been mapped for internal irradiation dosage under processing conditions in order to accurately measure tissue exposure. Following irradiation at 11.6-12.3 kGy for cortical bone or 11.6-12.9 kGy for tendon, respectively, the samples were returned to the testing facility and maintained at or below $-60^{\circ} \mathrm{C}$ until viral testing. For testing, the $1 \mathrm{~g}$ samples were homogenized (tendon) or suspended (bone) in a total of $9.5 \mathrm{~mL}$ virus resuspension media. A portion was diluted to non-toxic and non-interfering levels, as determined by toxicity and interference testing, serially diluted, and infectivity determined in the appropriate indicator cell line (see Table 1). Controls $\left(\right.$ Gamma- $\mathrm{T}_{\mathrm{o}}$ ) were similarly seeded, extracted as above, and samples maintained at or below $-60^{\circ} \mathrm{C}$ until final testing along with the test groups.

\section{Results}

The test methods were qualified using methods described in the "Methods" section and no interference or toxicity was noted towards any of the viruses at the experimentally pertinent dilution levels. In detail, no tissue extracts were found to be toxic to indicator cells at greater than a 10 -fold dilution. All test article extracts were diluted 20-fold for final titers, which was beyond any lower level of dilution which may have exhibited toxicity. Likewise, no diluted tissue extracts exhibited interference at greater than a threefold dilution, again, which was a lower level of dilution than the 20-fold dilution used for all test article extracts. In-process dosimetry verified the dose range at $11.6-12.3 \mathrm{kGy}$ for cortical bone samples and 11.6-12.9 kGy for tendon samples. Following seeding and gamma irradiation, the samples were tested as described. Three readings were taken per test sample. The log quantities of virus extracted from controls to gamma irradiated samples, as well as the seeding titer, are shown for tendon (Table 1) and bone (Table 2), respectively. In addition, rounded $\mathrm{D}_{10}$ value for the various viruses are also shown in Tables 1 and 2. Total log reduction was

Table 2 Viral reduction human cortical bone (all values in $\log$ )

\begin{tabular}{|c|c|c|c|c|c|}
\hline Virus & HIV & PPV & PrV & BVDV & HAV \\
\hline Indicator cell line & CEM-A & ST & CV-1 & BT & FrhK-4 \\
\hline Titer-seeded & 6.92 & 7.30 & 8.17 & 7.11 & 8.12 \\
\hline Gamma- $\mathrm{T}_{\mathrm{o}}$ & 5.77 & 7.11 & 8.01 & 7.01 & 8.28 \\
\hline Gamma-treated & $<2.57$ & 5.53 & 4.22 & 2.45 & 5.79 \\
\hline Total log reduction & $>3.20$ & 1.58 & 3.79 & 4.56 & 2.49 \\
\hline Approximate $D_{10}$ value & $<4$ & 8 & 3 & 3 & 5 \\
\hline
\end{tabular}

Viral reduction of seeded human cortical bone treated with gamma irradiation at low temperatures. Shown are the indicator cell lines, titer seeded onto allograft, titer of recovered virus from seeded grafts $\left(\right.$ Gamma- $\left.T_{0}\right)$, titer of recovered virus from seeded and irradiated grafts $\left(\right.$ Gamma- $\left.\mathrm{T}_{0}\right)$, and total $\log$ reduction (Gamma- $\mathrm{T}_{0}$ minus Gamma-treated). Also shown is a rounded approximate $\mathrm{D}_{10}$ value calculated by dividing the 11.6-12.3 kGy dose by the total log reduction and assuming a linear dose-response relationship 
Table 3 Virus test groups and $\log$ viral inactivation summary

\begin{tabular}{lllrr}
\hline Virus & Nucleic acid & Virus type & Bone & Tendon \\
\hline Human immunodeficiency virus (HIV) & RNA & Enveloped & $>3.20$ & $>2.90$ \\
Porcine parvovirus (PPV) & DNA & Non-enveloped & 1.58 & 1.90 \\
Pseudorabies virus (PrV) & DNA & Enveloped & 3.79 & 3.80 \\
Bovine viral diarrhea virus (BVDV) & RNA & Enveloped & 4.56 & 2.57 \\
Hepatitis A virus (HAV) & RNA & Non-enveloped & 2.49 & 2.54 \\
\hline
\end{tabular}

Total $\log$ reduction of viruses seeded on human tissue by gamma irradiation. Note the variety of viruses used including all permutations of DNA, RNA, enveloped, and non-enveloped viruses. The total log reduction as calculated in Tables 1 and 2 is summarized

considered the difference between the Gamma- $T_{o}$ and Gamma-treated sample titers. The irradiation dose tested, in the range of 11.6-12.9 kGy, yielded an approximate 2-5 log reduction of the various viruses tested, as summarized in Table 3. In detail, the viruses, virus types, and $\log$ reductions on seeded tendon and bone tissue, respectively, were as follows: HIV (RNA, enveloped), $>2.90$ and $>3.20$; PPV (DNA, non-enveloped), 1.90 and 1.58; PrV (DNA, enveloped), 3.80 and 3.79; BVDV (RNA, enveloped), 2.57 and 4.56; and HAV (RNA, non-enveloped), 2.54 and 2.49 , respectively. Thus, the hypothesis is proven that a low temperature, gamma irradiation process will inactivate DNA, RNA, enveloped, and nonenveloped viruses.

\section{Discussion}

The increased use of allograft tissue for musculoskeletal repair has brought more focus to the safety of allogeneic tissue and the efficacy of various sterilization techniques. As previously mentioned, the provision of sterile allograft tissue can be accomplished by following several steps which include donor screening, microbiological testing, aseptic recovery and processing, disinfection, and terminal sterilization (McAllister et al. 2007). One such method of terminal sterilization is gamma irradiation; which can provide both bactericidal and virucidal effects via direct alteration of nucleic acids leading to infectious agent dysfunction and destruction (Vangsness et al. 2003). Of particular interest, numerous reports indicate the inactivation of HIV with gamma irradiation (Campbell et al. 1994; Conway et al. 1991; Conway and Tomford 1992; Hiemstra et al. 1991; Pruss et al. 2002; Salai et al. 1997; Sullivan et al. 1973). While a few studies have concluded that at least $30 \mathrm{kGy}$ of gamma irradiation is needed to inactivate HIV (Fideler et al. 1994; Hernigou et al. 2000), these reports have assumed HIV is present in high density levels. While $30 \mathrm{kGy}$ may be necessary to inactivate high-density amounts of HIV, it is excessive for lower density levels of the virus that might be found, if at all, in medically screened, NAT tested, and disinfectant processed tissue. In example, Conway et al report a D-10 value for HIV of approximately $4 \mathrm{kGy}$ indicating a potential terminally sterilizing dose of 12 or $16 \mathrm{kGy}$ would yield 3 or $4 \log$ reduction of HIV. Again, the likelihood of any virus, much less large quantities following proper donor eligibility, medical history, and NAT testing is remote to begin with. As demonstrated here, an irradiation dose of $11.6-12.9 \mathrm{kGy}$ administered at low temperature yields an approximate 2-5 log reduction of the various viruses tested including a minimum of $3 \mathrm{log}$ reduction of HIV seeded on both tendon and bone tissues. Please note that this irradiation dosage may be at or below an actual dose used by a manufacturer to achieve terminal sterilization, and thus these values may be considered a worst case situation for log inactivation. To illustrate, if an allograft provider were to sterilize tissue at, e.g., 17.4-19.4 kGy (a 50\% higher dose than used in the study reported here) then the anticipated log reduction would rise $50 \%$ as well. This is significant as current allograft terminal sterilization methods may range from just over $10 \mathrm{kGy}$ up to as much as $50 \mathrm{kGy}$ (Block 2006). An additional reason for including a terminal irradiation step in allograft processing is to safeguard against those viruses which are currently not tested or are unknown. A study limitation is that individual tests were performed with a single sample of material. While this hampers any conclusion of 
statistical significance, note that accompanying controls (recovery, toxicity, and interference tests) were performed with tissue from the same donor to provide internal control. In addition, multiple readings were taken of each test sample increasing confidence in results. Another study limitation is the use of small tissue samples $(1 \mathrm{~g})$ and not whole bone or tendon allografts. While whole allografts would have been impractical to test, the relative viral load can be extrapolated from the small samples to a large graft. Enhancing the validity of the study, however, is that the test inactivation agent studied here is gamma irradiation which will fully penetrate tissue and is thus not dependent on tissue size or dimension.

\section{Conclusion}

Terminal sterilization of human allograft tissue using a low dose gamma irradiation process inactivates both enveloped and non-enveloped viruses containing either DNA or RNA. This final step in the processing of human allografts complements prior steps in providing additional assurance of viral safety.

Acknowledgments Special thanks to Melissa Harned (WuXi Apptec, Philadelphia, PA) who served as study co-designer and coordinator and Sherry Triplett and Brian Samsell (LifeNet Health, Virginia Beach, VA) for sample preparation and writing assistance, respectively.

Open Access This article is distributed under the terms of the Creative Commons Attribution Noncommercial License which permits any noncommercial use, distribution, and reproduction in any medium, provided the original author(s) and source are credited.

\section{References}

Anderson MJ, Keyak JH, Skinner HB (1992) Compressive mechanical properties of human cloward bone after gamma irradiation. J Bone Joint Surg Am 74(5):747-752

ANSI/AAMI ST67 : 2003/(R) (2008) Sterilization of health care products-requirements for products labeled. "STERILE"

Baker TF, Ronholdt CJ, Bogdansky S (2005) Validating a low dose gamma irradiation process for sterilizing allografts using ISO 11137 method 2B. Cell Tissue Bank 6(4):271-275

Balsly C, Cotter A, Williams L, Gaskins B, Moore M, Wolfinbarger L (2008) Effect of low dose and moderate dose gamma irradiation on the mechanical properties of bone and soft tissue allografts. Cell Tissue Bank 9(4):289-298
Block J (2006) The impact of irradiation on the microbiological safety, biomechanical properties, and clinical performance of musculoskeletal allografts. Orthopedics 29: 991-996

Campbell DG, Li P, Stephenson AJ, Oakeshott RD (1994) Sterilization of HIV by gamma irradiation. A bone allograft model. Int Orthop 18:172-176

Centers for Disease Control, Prevention (2002) Update: allograft-associated bacterial infections-US, 2002. MMWR Morb Mortal Wkly Rep 51(10):207-210

Chen, J. (2008) 5th World congress on tissue banking, June 2-6

Conway B, Tomford WW (1992) Radiosensitivity of human immunodeficiency virus type 1 . Clin Infect Dis 14:978979

Conway B, Tomford W, Mankin HJ, Hirsch MS, Schooley RT (1991) Radio-sensitivity of HIV-1: potential application to sterilization of bone allografts. AIDS 5:608-609

Dugan VL, Trujillo R (1975) Heat-accelerated radioinactivation of attenuated poliovirus. Radiat Environ Biophys 12:187-195

Fanelli G, Giannotti B, Edson C (1996) Arthroscopically assisted combined anterior and posterior cruciate ligament reconstruction. Arthoscopy 12(1):5-14

Fideler BM, Vangsness CT Jr, Moore T, Li Z, Rasheed S (1994) Effects of gamma irradiation on the human immunodeficiency virus. A study in frozen human bonepatellar ligament-bone grafts obtained from infected cadavera. J Bone Joint Surg Am 76:1032-1035

Fideler BM, Vangsness CT Jr, Lu B, Orlando C, Moore T (1995) Gamma irradiation effects on biomechanical properties of human bone-patellar tendon-bone allografts. Am J Sports Med 23(5):643-646

Gasser S, Uppal R. (2006) Anterior cruciate ligament reconstruction: a new technique for Achilles tendon allograft preparation. Arthroscopy 22(12):1365.el-3

Goertzen M, Clahsen H, Burrig K, Schulitz K (1995) Sterilization of canine anterior cruciate allografts by gamma irradiation in Argon. J Bone Joint Surg $\mathrm{Br} 77-\mathrm{B}(2)$ : 205-212

Greaves L, Hecker A, Brown C (2008) The effect of donor age and low-dose gamma irradiation on the initial biomechanical properties of human tibialis tendon allografts. Am J Sports Med 36(7):1358-1366

Grecz N, Brannon R, Killgore G (1987) Radiation sterilization of surgical instruments with a consideration of metal shielding on sterilization efficiency. Am J Infect Control 15:101-106

Grieb TA, Forng RY, Stafford RE, Lin J, Almeida J, Bogdansky S, Ronholdt C, Drohan WN, Burgress WH (2005) Effective use of optimized, high dose (50 kGy) gamma irradiation for pathogen inactivation of human bone allografts. Biomaterials 26(14):2033-2042

Grieb TA, Forng RY, Bogdansky S, Ronholdt C, Parks B, Drohan WN, Burgess WH, Lin J (2006) High-dose gamma irradiation for soft tissue allografts: high margin of safety with biomechanical integrity. J Orthop Res 24(5):1011-1018

Hamer AJ, Stockey I, Elson RA (1999) Changes in allograft bone irradiated at different temperatures. J Bone Joint Surg Br 81(2):342-344 
Hernigou P, Gras G, Marinello G, Dormont D (2000) Influence of irradiation on the risk of transmission of HIV in bone grafts obtained from appropriately screened donors and followed by radiation sterilization. Cell Tissue Bank $1: 279-289$

Hiemstra H, Tersmette M, Vos AH, Over J, van Berkel MP, de Bree H (1991) Inactivation of human immunodeficiency virus by gamma radiation and its effect on plasma and coagulation factors. Transfusion 31(1):32-39

House C, House JA, Yedloutschnig RJ (1990) Inactivation of viral agents in bovine serum by gamma irradiation. Can J Microbiol 36L:737-740

Jones DB, Huddleston PM, Zobitz ME, Stuart MJ (2007) Mechanical properties of patellar tendon allografts subjected to chemical sterilization. Arthroscopy 23(4):400-404

Joyce MJ, Greenwald AS, Boden S, Brubaker S, Heim CS (2008) For the committee on patient safety, committee on biological implants, and tissue work group. musculoskeletal allograft tissue safety. Handout presented at: American Academy of Orthopaedic Surgeons, Chicago, March 2008

Kainer MA, Linden JV, Whaley DN, Holmes HT, Jarvis WR, Jernigan DB, Archibald LK (2004) Clostridium infections associated with musculoskeletal-tissue allografts. N Eng J Med 350(25):2564-2571

Kaupert N, Burgi E, Scolaro L (1999) Inactivation of poliovirus by gamma irradiation of wastewater sludges. Rev Argent Microbiol 31:49-52

McAllister DR, Joyce JJ, Mann BJ, Vangsness CT (2007) Allograft update: the current status of tissue regulation, procurement, processing, and sterilization. Am J Sports Med 35(12):2148-2158

McGilvray K, Lewis C, Wheeler D (2005) Effects of irradiation dose on the initial structural biomechanical properties. Properties of ovine bone- patellar tendon- bone allografts. 51st Annual Meeting of the Orthopaedic Research Society 30; 0726

McGuire D, Hendricks S (2009) Allograft tissue in ACL reconstruction. Sports Med Arthrosc 17:224-233

Miekka SI, Busby TF, Reid B, Pollock R, Ralston A, Drohan WN (1998) New methods for inactivation of lipid-enveloped and non-enveloped viruses. Haemophilia 4:402-408

Mirzayan R (2005) Role of allografts in primary ACL reconstruction. Medscape. http://www.medscape.org/view article/515090

Moore M, Linthurst Jones A, Gaskins B, Wolfinbarger L (2004) Adaptation of ANSI/AAMI/ISO 11137 method 2B sterilization validation for medical devices to tissue banking. In: American Association of Tissue Banks Annual Meeting, Chicago, p S-20

Nguyen H, Morgan DA, Forwood MR (2011) Validation of $11 \mathrm{kGy}$ as a radiation sterilization dose for frozen bone allografts. J Arthroplasty 26(2):303-308

Pelka A, Olsberg C, Miller S, Waltenbaugh C, Creighton TM, dal Canto MC, Melvold R (1993) Effects of irradiation on development of theiler's murine encphalomyelitis (TMEV)-induced demyelinationg disease in genetically resistant mice. Cell Immunol 152:440-455

Peterson RK, Shelton WR, Bomboy AL (2001) Allograft versus autograft patellar tendon anterior cruciate ligament reconstruction: a 5-year follow up. Arthroscopy 17(1): $9-13$

Pruss A, Kao M, Gohs U, Koscielny J, von Versen R, Pauli G (2002) Effect of gamma irradiation of human cortical bone transplants contaminated with enveloped and nonenveloped viruses. Biologicals 30:125-133

Rigney PR (2004) AATB Bulletin No. 04-42 - Implementation of nucleic acid testing (NAT). Available online at: http:// www.aatb.org/files/2004bulletin42.pdf. Accessed 25 Sep 2007

Rihn JA, Irrgang JJ, Chhabra A, Fu FH, Harner CD (2006) Does irradiation affect the clinical outcome of patellar tendon allograft ACL reconstruction? Knee Surg Sports Traumatol Arthrosc 14(9):885-896

Salai M, Vonsover A, Pritch M, von Versen R, Horoszowski H (1997) Human immunodeficiency virus inactivation of banked bone by gamma irradiation. Ann Transplant 2(1):55-56

Shino K, Horibe S, Hamada M, Nakamura N, Nakata K, Toritsuka Y, Mae T (2002) Allograft anterior cruciate ligament reconstruction. Tech Knee Surg 1:78-85

Stramer SL, Glynn SA, Kleinman SH, Strong DM, Caglioti S, Wright DJ, Dodd RY, Busch MP, National Heart, Lung, and Blood Institute Nucleic Acid Test Study Group (2004) Detection of HIV-I and HCV infections among antibodynegative blood donors by nucleic acid-amplification testing. N Eng J Med 351(8):760-768

Sullivan R, Scarpino PV, Fassolitis AC, Larkin EP, Peeler JT (1973) Gamma radiation inactivation of Coxsakievirus B-2. Appl Microbiol 26(1):14-17

Thomas FC, Ouwerkerk T, McKercher P (1982) Inactivation by gamma irradiation of animal viruses in simulated laboratory effluent. Appl Environ Microbiol 43(5):1051-1056

Vangsness CT Jr, Garcia IA, Mills CR, Kainer MA, Roberts MR, Moore TM (2003) Allograft transplantation in the knee: tissue regulation, procurement, processing, and sterilization. Am J Sports Med 31(3):474-481

Vangsness CT Jr, Wagner PP, Moore TM, Roberts MR (2006) Overview of safety issues concerning the preparation and processing of soft-tissue allografts. Arthroscopy 22(12): $1351-1358$

US Patents 5,556,379; 5,820,581; 5,977,034; 6,024,735

Zhang YX, Homsi D, Gates K, Oakes K, Sutherland V, Wolfinbarger L Jr (1994) A comprehensive study of physical parameters, biomechanical properties and statistical correlations of iliac crest wedges used in spinal fusion surgery. IV: effect of gamma irradiation on mechanical strength. Spine 19(3):304-308 